\title{
Edaphic factors controlling soil organic matter and C storage in miombo woodlands, Zambia
}

\author{
Reuben Lembani ${ }^{1}$ and Jasper Knight ${ }^{2}$ \\ ${ }^{1}$ Copperbelt College of Education \\ ${ }^{2}$ University of the Witwatersrand
}

May 3, 2021

\begin{abstract}
Soil organic matter (SOM) is a key component of forest productivity and soil organic carbon stock. However, little is known about SOM and C variability in miombo woodlands which is a significant ecosystem in sub-Sahara African forests and vital for REDD+ strategies. In this study, nine edaphic factors were measured and used to analyse the variability of SOM in miombo woodland sites with different tree structures in Luanshya, Zambia. The findings showed a large variability of SOM stocks at different soil depths: 36.67 to $113.89 \mathrm{Mg}$ ha- 1 at 0-10 $\mathrm{cm}$ depth, 28.67 to $79.56 \mathrm{Mg}$ ha-1 at $10-20 \mathrm{~cm}$ depth, and 31.89 to $98.56 \mathrm{Mg}$ ha-1 at 20-30 cm depth. These SOM values at different depths also varied between miombo woodland sites of different successional stages, notably that areas affected by recent tree clearance had higher than average SOM content per layer $(0-10 \mathrm{~cm}:+5.57 \% ; 10-20 \mathrm{~cm}:+4.20 \% ; 20-30 \mathrm{~cm}:+4.30 \%)$. Canonical correspondence analysis (CCA) revealed that the most significant environmental factors influencing SOM were woodland thinning by clearance, and silt content within soils. This study highlights that CCA can be used to show the relative importance of different forest successional stages as a function of management practices, as well as edaphic factors, in determining miombo soil SOM content. The results of this study are particularly relevant for addressing current REDD+ reforestation and management strategies that are aimed at increasing carbon stocks in the tropical forests of sub-Saharan Africa.
\end{abstract}

\section{Hosted file}

Miombo SOM_LR \& JK.pdf available at https://authorea.com/users/411597/articles/520568edaphic-factors-controlling-soil-organic-matter-and-c-storage-in-miombo-woodlands-zambia 

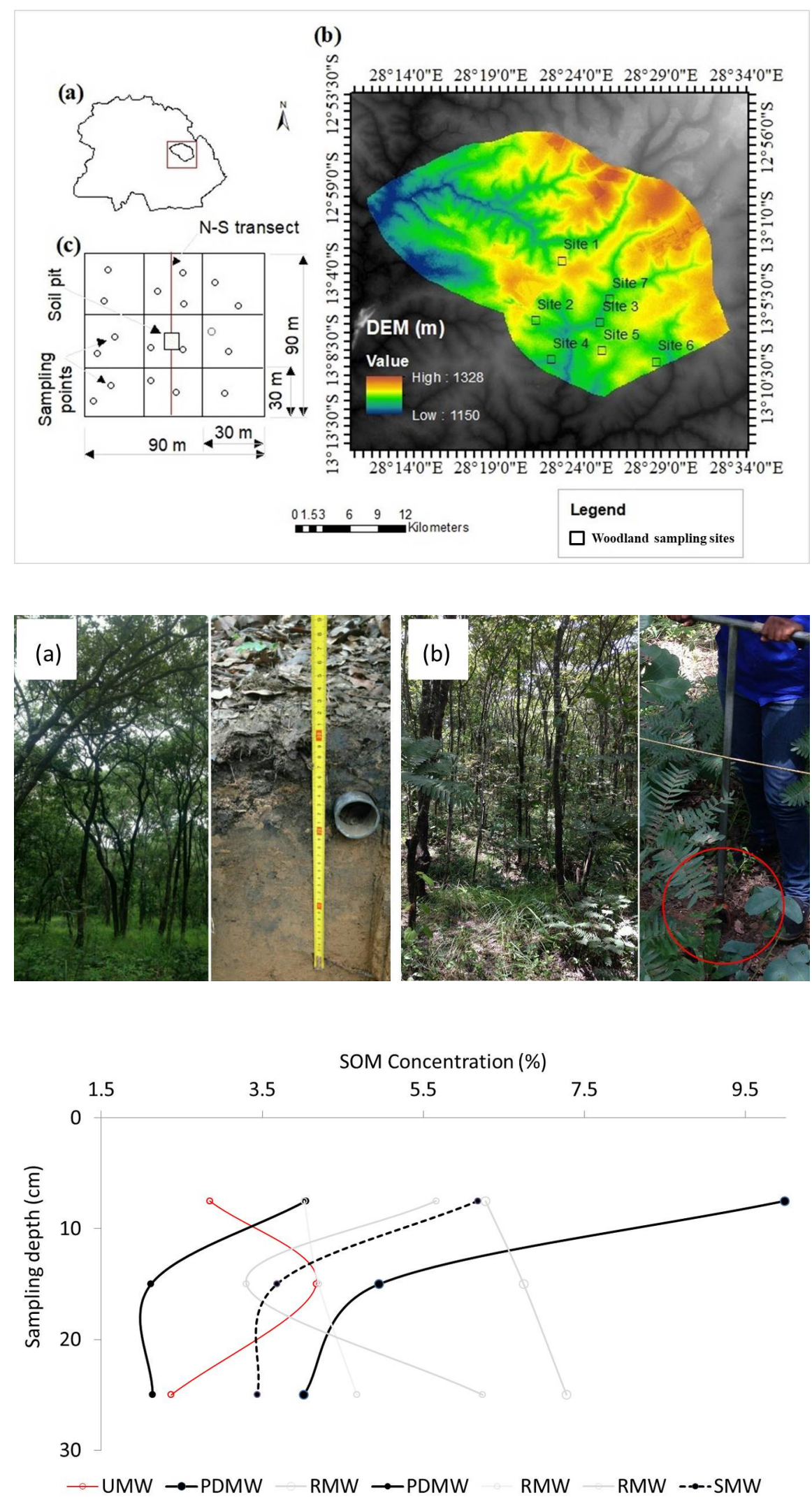


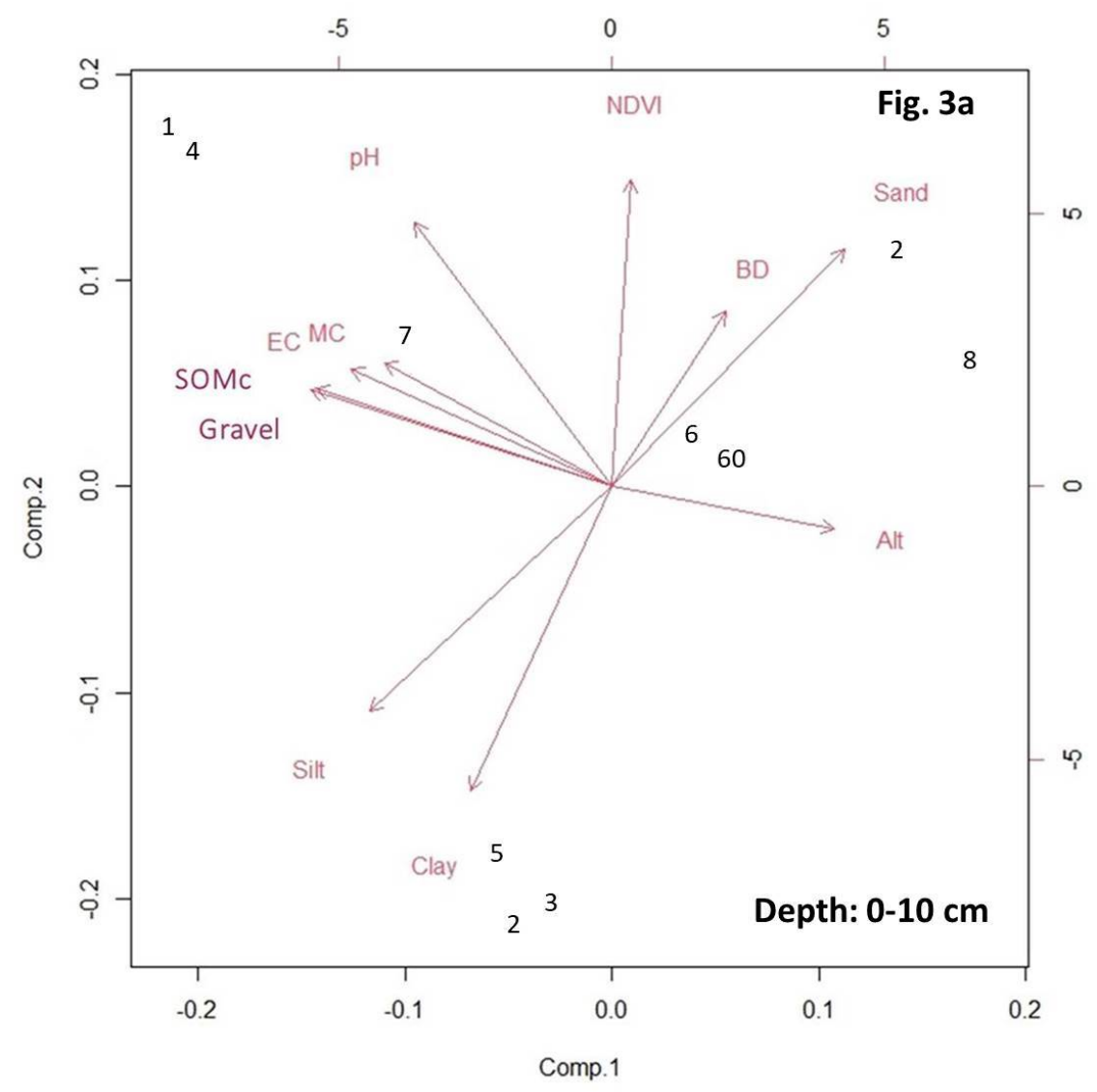

